\title{
Prognostic Impact of PD-L2 Expression and Association with PD-L1 in Patients with Small-cell Lung Cancer
}

\author{
SHINKICHI TAKAMORI ${ }^{1}$, KAZUKI TAKADA $^{2}$, KOICHI AZUMA $^{3}$, YUMIKO JOGO $^{1,4}$, \\ FUMIHIKO KINOSHITA ${ }^{1}$, YUKA KOZUMA ${ }^{1}$, TAICHI MATSUBARA ${ }^{1}$, NAOKI HARATAKE ${ }^{1}$, \\ TAKAKI AKAMINE ${ }^{1}$, GOUJI TOYOKAWA ${ }^{1}$, FUMIHIKO HIRAI ${ }^{1}$, TETSUZO TAGAWA $^{1}$, ISAMU OKAMOTO ${ }^{5}$, \\ YOICHI NAKANISHI ${ }^{5}$, AKIHIKO KAWAHARA ${ }^{6}$, JUN AKIBA $^{6}$, YOSHINAO ODA $^{4}$ and YOSHIHIKO MAEHARA ${ }^{1}$ \\ ${ }^{1}$ Department of Surgery and Science, Graduate School of Medical Sciences, Kyushu University, Fukuoka, Japan; \\ ${ }^{2}$ Department of Thoracic Oncology, National Kyushu Cancer Center, Fukuoka, Japan; \\ ${ }^{3}$ Division of Respirology, Neurology, and Rheumatology, \\ Department of Internal Medicine, Kurume University School of Medicine, Fukuoka, Japan; \\ ${ }^{4}$ Department of Anatomic Pathology, Graduate School of Medical Sciences, Kyushu University, Fukuoka, Japan; \\ ${ }^{5}$ Research Institute for Disease of the Chest, Graduate School of Medical Sciences, \\ Kyushu University, Fukuoka, Japan; \\ ${ }^{6}$ Department of Diagnostic Pathology, Kurume University School of Medicine, Fukuoka, Japan
}

\begin{abstract}
Background/Aim: Although some previous studies suggested that programmed cell death-ligand 1 (PD-L1) expression was significantly associated with a favorable postoperative prognosis in patients with smallcell lung cancer (SCLC), the prognostic significance of PD$L 2$ expression remains unknown. The aim of the current study was to investigate the prognostic significance of $P D$ L2 expression in patients with SCLC. Patients and Methods: Thirty-eight patients who underwent resection of SCLC were analyzed. A monoclonal anti-human PD-L1 antibody (clone SP142) and a monoclonal anti-human PDL2 antibody (clone 176611) were used as the primary antibodies. Cut-off value for PD-L1 and PD-L2 expression was set to 1\%. Results: Among 38 patients, 15 (39.5\%) were positive for PD-L2 expression. No significant associations between PD-L2-positivity and clinicopathological factors, including PD-L1 positivity or prognosis were identified. No significant differences in disease-free survival and overall survival were observed between PD-L2-positive patients and PD-L2-negative patients ( $p=0.367$ and $p=0.726$, respectively). Conclusion:
\end{abstract}

Correspondence to: Kazuki Takada, Department of Thoracic Oncology, National Kyushu Cancer Center, 3-1-1 Notame, Minamiku, Fukuoka 811-1395, Japan. Tel: +81 925413231, Fax: +81 925514585, e-mail: takadakazuki1077@gmail.com

Key Words: Programmed death ligand 2, programmed death ligand 1 , lung adenocarcinoma; immunohistochemistry, surgery.
PD-L2 expression is not related to clinicopathological factors or postoperative prognosis in patients with SCLC, though this should be further investigated in studies involving larger populations.

Lung cancer is one of the most fatal malignancies worldwide (1), with small-cell lung cancer (SCLC) accounting for $15-20 \%$ of cases (2), representing a devastating subtype of lung cancer (3). In addition to a standard-of-care including chemotherapy, radiotherapy, and surgical resection $(3,4)$, immunotherapy targeting programmed death 1 (PD-1) has recently been attracting attention as a therapeutic option for SCLC (5), and an antiPD-1 drug has demonstrated promising antitumor activity in pretreated patients with programmed death-ligand 1 (PDL1)-positive SCLC (5).

Programmed death-ligand 2 (PD-L2), another PD-1 ligand, is expressed mainly on dendritic cells, macrophages, and tumor cells (6). PD-L2 protein provokes downregulation of the effector functions of $\mathrm{T}$ cells via the $\mathrm{PD}$ 1/PD-L2 axis (6). Although some previous studies suggested that PD-L1 expression was significantly associated with a favorable postoperative prognosis in patients with SCLC (7, 8), the prognostic significance of PD-L2 expression remains unknown. We, therefore, conducted a retrospective study to investigate PD-L2 expression in 38 patients with surgically resected SCLC. The associations between PD-L2-positivity and clinicopathological factors were analyzed to determine if PD-L2 expression was associated with disease-free survival (DFS) and overall survival (OS). 


\section{Materials and Methods}

Patients and samples. Sixty-two patients underwent complete resection of SCLC at the Department of Surgery and Science, Graduate School of Medical Sciences, Kyushu University (Fukuoka, Japan) from April 1974 to August 2015. Among these, 38 patients for whom resected specimens were available for immunohistochemical analysis of PD-L2 were investigated in the current study. The patient characteristics analyzed included age, sex, smoking history, surgical procedure, pathological stage (pStage), pleural invasion, lymphatic invasion and vascular invasion. Pathological stage was determined according to the 7 th edition of the TNM Classification of Malignant Tumors. This study was approved by the institutional review board of our institution (Kyushu University, IRB No. 29-261).

Immunohistochemical analysis of PD-L1 and PD-L2 expression levels in tumor specimens. We determined the expression levels of PD-L1 and PD-L2 in tumor tissues by immunohistochemical analysis of formalinfixed, paraffin-embedded tissue sections. Immunohistochemical analysis was conducted using commercial antibodies against PD-L1 (clone SP142, dilution 1:100; Spring Bioscience, Ventana, Tucson, AZ, USA) and PD-L2 (clone 176611, dilution 1:200; R\&D systems, Inc., Minneapolis, MN, USA). Immunohistochemistry for PD-L1 was performed as described previously (9). With regard to immunohistochemistry for PD-L2, 4- $\mu$ m sections were prepared and mounted on glass slides using a B Bond-III autostainer (Leica Microsystems, Newcastle, UK). Briefly, tissues were stained with mouse monoclonal anti-human PD-L2 antibody (clone 176611, dilution 1:200; R\&D systems, Inc.) by treating with proteinase $\mathrm{K}$ (Agilent/Dako, CA, USA) for $5 \mathrm{~min}$ followed by incubation with antibody for $30 \mathrm{~min}$. This automated system used a Refine polymer detection system (Leica Microsystems) with horseradish peroxidasepolymer as secondary antibody. The slides were visualized using 3,3, diaminobenzidine as the chromogen.

Immunostaining for PD-L1 and PD-L2 was evaluated in the membranes of the tumor cells (Figure 1). The proportions of carcinoma cells positive for PD-L1 and PD-L2 were estimated as percentages of all carcinoma cells in the whole sections. All immunohistochemical images were evaluated independently by two investigators (S.T. and K.T.) who were unaware of the outcomes, and the consensus judgment was used for further analyses. We set the cut-off values of both PD-L1- and PD-L2-positivity as 1\% (9).

Statistical analyses. The associations between PD-L2 expression and the clinicopathological factors were analyzed using Fisher's exact two-sided test. The probability of survival was estimated using the Kaplan-Meier method and log-rank test. $p$-Values of $<0.05$ were considered to indicate statistical significance. All the analyses were performed using the $\mathrm{JMP}^{\circledR}$ software, ver. 13 (SAS Institute Inc., Cary, NC, USA).

\section{Results}

Associations between PD-L2 protein expression and clinicopathological characteristics in patients with SCLC. The characteristics of all 38 patients who were diagnosed with SCLC and who underwent curative surgical resection are shown in Table I. In brief, the median age was 68 years (range $=48-84$ years) and 32 patients $(84.2 \%)$ were men. Thirty-three patients $(89.2 \%)$ had a smoking history. Fifteen $(30.5 \%)$ and $21(55.3 \%)$ patients had T1 and N0 disease, respectively, 29 patients $(82.4 \%)$ received lobectomy, and 18 patients (47.4\%) were diagnosed as pStage I. Pleural, lymphatic, and vascular invasion were observed in 14 $(40.0 \%), 11(29.7 \%)$, and $20(54.1 \%)$ patients, respectively. Six patients $(15.8 \%)$ were positive for PD-L1 expression. The associations between PD-L2 positivity and the various patient characteristics are shown in Table II. Fifteen patients (36.8\%) were positive for PD-L2 expression at a cut-off value of $1 \%$. There was no significant association between PD-L2 positivity and any of the tested patient characteristics. The relationships between PD-L2-positivity and clinicopathological factors were also non-significant with a cut-off value for PD-L2 expression of 5\% (data not shown).

Univariate survival analysis of DFS and OS according to $P D-L 2$ protein expression in patients with SCLC. The associations between PD-L2 protein expression and DFS and OS were analyzed at a PD-L2 cut-off value of $1 \%$. No significant differences in DFS and OS were observed between PD-L2-positive patients and PD-L2-negative patients ( $p=0.367$ and $p=0.726$, respectively) (Figure $2 \mathrm{a}$ and $\mathrm{b}$ ). There were also no significant differences in DFS or OS in relation to PD-L2 positivity in a subgroup analysis of PD-L1-negative patients with cut-off values of $1 \%(p=0.450$ and $p=0.414$, respectively) (Figure 2c and d) or 5\% (data not shown).

\section{Discussion}

To the best of our knowledge, this study is the first to report on the postoperative prognostic impact of PD-L2-positivity in patients with SCLC. However, although PD-L2 expression showed no significant associations with patient characteristics or postoperative prognosis, the sample size was too small to draw any definitive conclusions.

PD-1 and its ligands, PD-L1 and PD-L2, downregulate the signals that control T-cell activation, leading to attenuation of tumor immunity and facilitating tumor survival (6). In contrast to expectations however, we previously revealed that PD-L1-positivity was significantly associated with early $\mathrm{T}$ stage (7). Ishii et al. also reported a relationship between PDL1-positivity and limited disease stage (8). Regarding prognosis, both of these above studies found a favorable prognosis in PD-L1-positive SCLC patients compared with PD-L1-negative ones $(7,8)$. However, PD-L2-positivity was not related to any clinicopathological factors associated with progressive cancer status in the current study. Additionally, no significant differences in DFS and OS were observed between PD-L2-positive patients and PD-L2-negative patients (Figures 2a, b), though further prospective studies with larger sample sizes are needed to verify these findings. 
Table I. Patient characteristics $(n=38)$.

\begin{tabular}{|c|c|}
\hline Factors & Value or no. of patients \\
\hline \multicolumn{2}{|l|}{ Age (years) } \\
\hline Median & 68 \\
\hline Range & $48-84$ \\
\hline \multicolumn{2}{|l|}{ Gender $(\mathrm{N})$} \\
\hline Men & 32 \\
\hline Women & 6 \\
\hline \multicolumn{2}{|l|}{ Smoking status $(\mathrm{N})^{*}$} \\
\hline Never & 4 \\
\hline Ever & 33 \\
\hline \multicolumn{2}{|l|}{$\mathrm{T}(\mathrm{n})$} \\
\hline $\mathrm{T} 1$ & 15 \\
\hline$\geq \mathrm{T} 2$ & 23 \\
\hline \multicolumn{2}{|l|}{$\mathrm{N}(\mathrm{n})$} \\
\hline No & 21 \\
\hline$\geq \mathrm{N} 1$ & 17 \\
\hline \multicolumn{2}{|l|}{ Surgical procedure $(n)^{*}$} \\
\hline Lobectomy & 28 \\
\hline Sublobar resection & 6 \\
\hline \multicolumn{2}{|l|}{ Pathological stage (n) } \\
\hline I & 18 \\
\hline$\geq \mathrm{II}$ & 20 \\
\hline \multicolumn{2}{|l|}{$\mathrm{pl}(\mathrm{n})^{*}$} \\
\hline Absent & 21 \\
\hline Present & 14 \\
\hline \multicolumn{2}{|l|}{ ly $(n)^{*}$} \\
\hline Absent & 26 \\
\hline Present & 11 \\
\hline \multicolumn{2}{|l|}{$\mathrm{v}(\mathrm{n})^{*}$} \\
\hline Absent & 17 \\
\hline Present & 20 \\
\hline \multicolumn{2}{|l|}{ PD-L1 (n) } \\
\hline Negative & 32 \\
\hline Positive & 6 \\
\hline
\end{tabular}

*Cases for which data were available. Pl: Pleural invasion; ly: lymphatic invasion; v: vascular invasion; PD-L1: programmed death-ligand 1.
Table II. Associations between PD-L2 protein expression and clinicopathological factors in patients with SCLC $(n=38)$.

\begin{tabular}{|c|c|c|c|}
\hline Factors & $\begin{array}{l}\text { PD-L2 negative } \\
\quad(\mathrm{n}=23)\end{array}$ & $\begin{array}{l}\text { PD-L2 positive } \\
\quad(\mathrm{n}=15)\end{array}$ & $p$-Value \\
\hline \multicolumn{4}{|l|}{ Age (years) } \\
\hline Mean (SD) & $69.7(6.8)$ & $66.5(10.3)$ & $0.250^{\mathrm{a}}$ \\
\hline \multicolumn{4}{|l|}{ Gender (n) } \\
\hline Man $(n=32)$ & $20(87.0 \%)$ & $12(80.0 \%)$ & \multirow[t]{2}{*}{$0.663 b$} \\
\hline Woman $(n=6)$ & $3(13.0 \%)$ & $3(20.0 \%)$ & \\
\hline \multicolumn{4}{|l|}{ Smoking status $(\mathrm{n})^{*}$} \\
\hline Never $(n=4)$ & $2(8.7 \%)$ & $2(14.3 \%)$ & \multirow[t]{2}{*}{$0.625 \mathrm{~b}$} \\
\hline Ever $(n=33)$ & $21(91.3 \%)$ & $12(85.7 \%)$ & \\
\hline \multicolumn{4}{|l|}{$\mathrm{T}(\mathrm{n})$} \\
\hline $\mathrm{T} 1(\mathrm{n}=15)$ & $9(39.1 \%)$ & $6(40.0 \%)$ & \multirow[t]{2}{*}{$1.000 \mathrm{~b}$} \\
\hline$\geq \mathrm{T} 2(\mathrm{n}=23)$ & $14(60.9 \%)$ & $9(60.0 \%)$ & \\
\hline \multicolumn{4}{|l|}{$\mathrm{N}(\mathrm{n})$} \\
\hline No $(n=21)$ & $14(60.9 \%)$ & $7(46.7 \%)$ & \multirow[t]{2}{*}{$0.509 b$} \\
\hline$\geq \mathrm{N} 1(\mathrm{n}=17)$ & $9(39.1 \%)$ & $8(53.3 \%)$ & \\
\hline \multicolumn{4}{|c|}{ Pathological stage (n) } \\
\hline $\mathrm{I}(\mathrm{n}=18)$ & $12(52.2 \%)$ & $6(40.0 \%)$ & \multirow[t]{2}{*}{$0.522 \mathrm{~b}$} \\
\hline$\geq \mathrm{II}(\mathrm{n}=20)$ & $11(47.8 \%)$ & $9(60.0 \%)$ & \\
\hline \multicolumn{4}{|l|}{$\mathrm{pl}(\mathrm{n})^{*}$} \\
\hline Absent $(n=21)$ & $14(66.7 \%)$ & $7(50.0 \%)$ & \multirow[t]{2}{*}{$0.483^{\mathrm{b}}$} \\
\hline Present $(n=14)$ & $7(33.3 \%)$ & $7(50.0 \%)$ & \\
\hline \multicolumn{4}{|l|}{ ly $(n)^{*}$} \\
\hline Absent $(n=26)$ & $17(77.3 \%)$ & $9(60.0 \%)$ & \multirow[t]{2}{*}{$0.296^{\mathrm{b}}$} \\
\hline Present $(n=11)$ & $5(22.7 \%)$ & $6(40.0 \%)$ & \\
\hline \multicolumn{4}{|l|}{$\mathrm{v}(\mathrm{n})^{*}$} \\
\hline Absent $(\mathrm{n}=17)$ & $11(50.0 \%)$ & $6(40.0 \%)$ & \multirow[t]{2}{*}{$0.738^{\mathrm{b}}$} \\
\hline Present $(n=20)$ & $11(50.0 \%)$ & $9(60.0 \%)$ & \\
\hline \multicolumn{4}{|l|}{ PD-L1 (n) } \\
\hline Negative $(n=32)$ & $20(87.0 \%)$ & $12(80.0 \%)$ & \multirow[t]{2}{*}{$0.663^{\mathrm{b}}$} \\
\hline Positive $(n=6)$ & $3(13.0 \%)$ & $3(20.0 \%)$ & \\
\hline
\end{tabular}

*Cases for which data were available. SCLC: Small-cell lung cancer; PD-L1: programmed death-ligand 1; PD-L2: programmed death-ligand 2; SD: standard deviation; pl: pleural invasion; ly: lymphatic invasion;

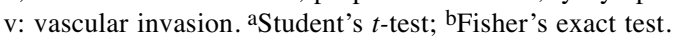

A previous retrospective study revealed that PD-L2 expression was associated with the clinical response to immunotherapy in patients with head and neck squamous cell carcinoma (10). However, PD-L2-positivity and its relationship with the response to anti-PD-1 drugs has not been elucidated in SCLC. Given that PD-L2-positivity was not related to that of PD-L1, and that the prognostic impacts of PD-L1 and PD-L2 expression seemed to differ, further studies are also needed to investigate the potential role of PD-L2 expression as a predictive biomarker of the response to immunotherapy $(7,8)$.

The current study had several limitations. One major weakness of this study was the very small number of patients. However, it should be emphasized that this was the first study to investigate the prognostic significance of PD-
L2 expression in SCLC patients, and further studies with larger numbers of patients may help to reveal the potential role of PD-L2-positivity in SCLC. Second, only the SP142 and 176611 clones were used as primary antibodies for evaluating PD-L1 and PD-L2 expression, respectively. Although clone SP142 has been reported to show greater positivity than other antibodies such as E1L3N and 28-8 (11), PD-L1 and PD-L2 expression should be investigated using other antibodies in further prospective studies.

In conclusion, our study found no significant association between PD-L2 expression and clinicopathological factors or postoperative prognosis in patients with SCLC. However, given the small sample size, the clinical impact of PD-L2positivity should be elucidated in further studies with larger populations. 
a

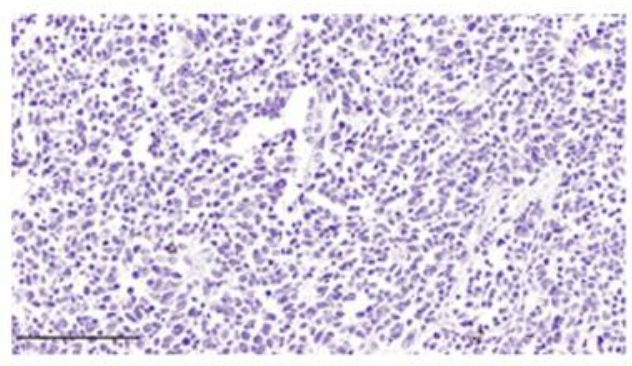

C

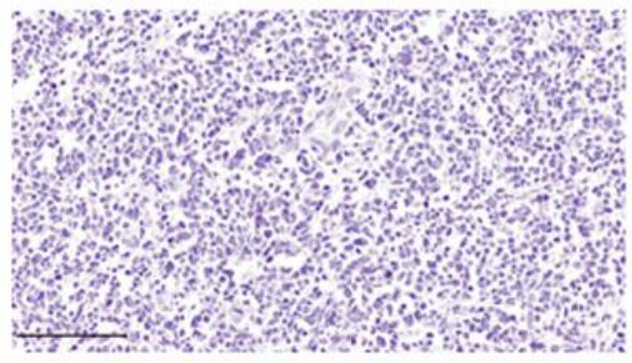

b

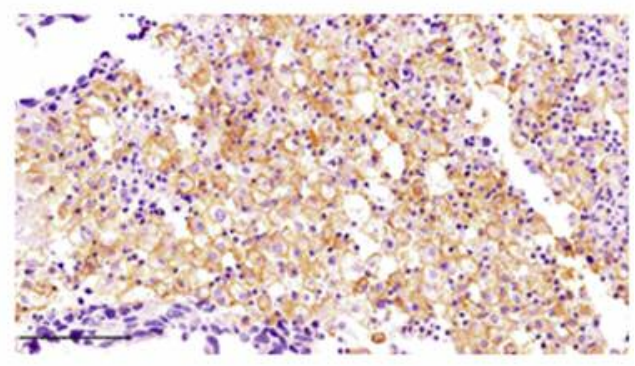

d

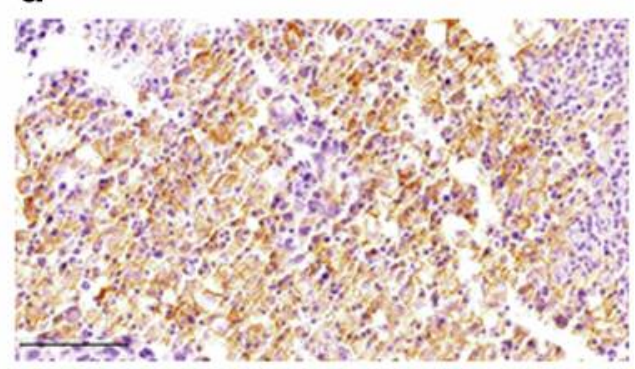

Figure 1. Immunohistochemical staining of programmed death-ligand 1 (PD-L1) and programmed death-ligand 2 (PD-L2) in patients with smallcell lung cancer. (a) Negative staining for PD-L1. (b) Representative image of PD-L1-positive case. (c) Negative staining for PD-L2. (d) Representative image of PD-L2-positive case. Scale bar $=100 \mu \mathrm{m}$.
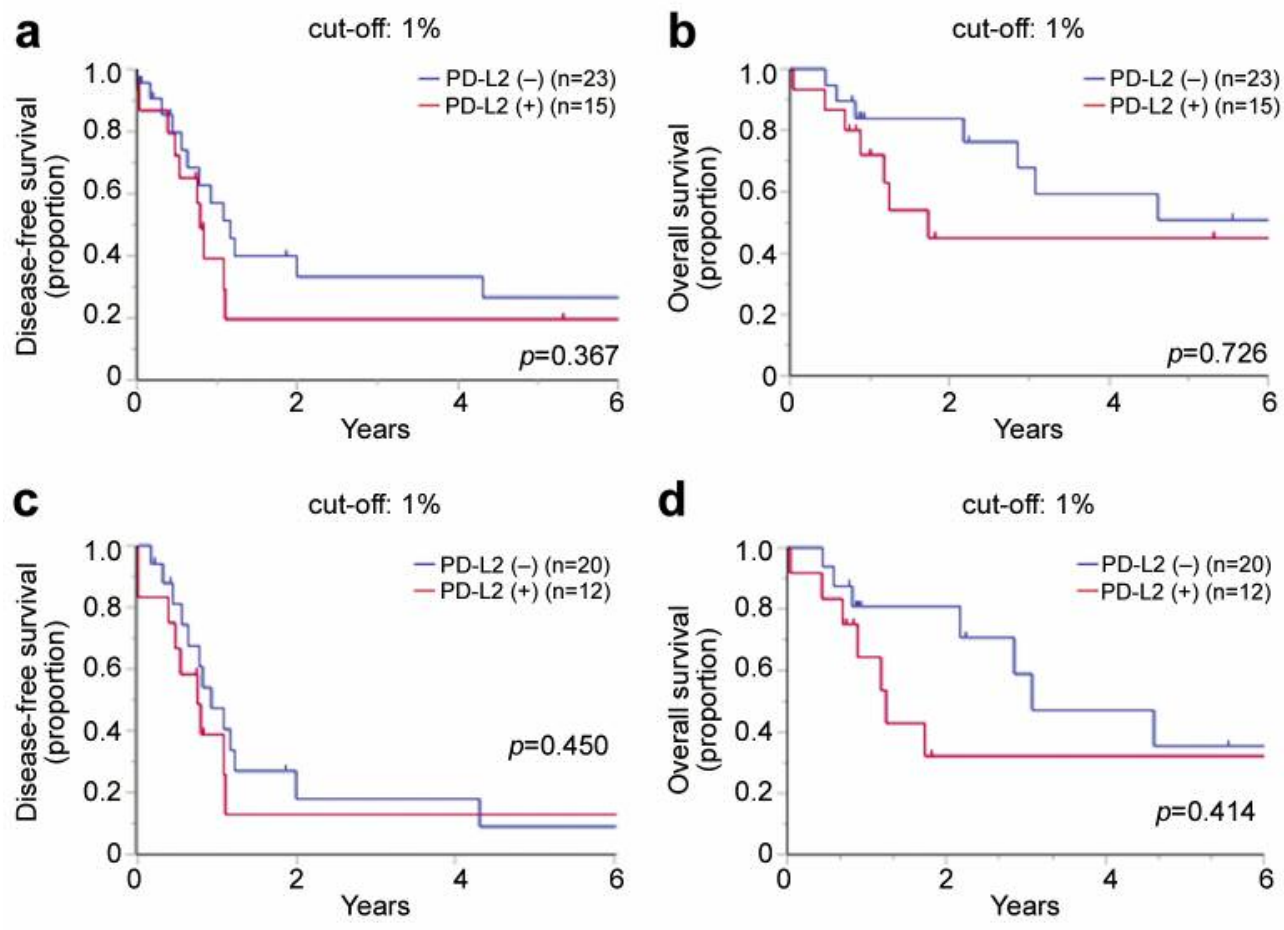

Figure 2. Kaplan-Meier curves showing survival of patients with small-cell lung cancer according to the expression of programmed death-ligand 2 (PD-L2). (a) Disease-free survival and (b) overall survival in all SCLC patients according to PD-L2 expression status with a cut-off value of 1\%. (c) Disease-free survival and (d) overall survival in PD-L1-negative SCLC patients (cut-off value: 1\%) according to PD-L2 expression status with a cut-off value of $1 \%$. 


\section{Acknowledgements}

The Authors would like to thank Susan Furness, PhD, from Edanz Group (www.edanzediting.com/ac) for editing a draft of this manuscript.

\section{References}

1 Torre LA, Bray F, Siegel RL, Ferlay J, Lortet-Tieulent J and Jemal A: Global cancer statistics, 2012. CA Cancer J Clin 65: 87-108, 2015 .

2 Ettinger DS: Overview and state of the art in the management of lung cancer. Oncology (Williston Park, NY) 18: 3-9, 2004.

3 Byers LA and Rudin CM: Small cell lung cancer: where do we go from here? Cancer 121: 664-672, 2015.

4 Takenaka T, Takenoyama M, Inamasu E, Yoshida T, Toyokawa G, Nosaki K, Hirai F, Yamaguchi M, Shimokawa M, Seto T and Ichinose Y: Role of surgical resection for patients with limited disease-small cell lung cancer. Lung Cancer 88: 52-56, 2015.

5 Ott PA, Elez E, Hiret S, Kim DW, Morosky A, Saraf S, Piperdi $\mathrm{B}$ and Mehnert JM: Pembrolizumab in patients with extensivestage small-cell lung cancer: Results from the Phase $\mathrm{Ib}$ KEYNOTE-028 Study. J Clin Oncol 35: 3823-3829, 2017.

6 Keir ME, Butte MJ, Freeman GJ and Sharpe AH: PD-1 and its ligands in tolerance and immunity. Ann Rev Immunol 26: 677704, 2008 .

7 Toyokawa G, Takada K, Haratake N, Takamori S, Akamine T, Katsura M, Fujishita T, Shoji F, Okamoto T, Oda Y and Maehara Y: Favorable disease-free survival associated with programmed death ligand 1 expression in patients with surgically resected small-cell lung cancer. Anticancer Res 36: 4329-4336, 2016.
8 Ishii H, Azuma K, Kawahara A, Yamada K, Imamura Y, Tokito T, Kinoshita $T$, Kage $M$ and Hoshino T: Significance of programmed cell death-ligand 1 expression and its association with survival in patients with small cell lung cancer. J Thorac Oncol 10: 426-430, 2015.

9 Takada K, Okamoto T, Shoji F, Shimokawa M, Akamine T, Takamori S, Katsura M, Suzuki Y, Fujishita T, Toyokawa G, Morodomi Y, Okano S, Oda Y and Maehara Y: Clinical significance of PD-L1 protein expression in surgically resected primary lung adenocarcinoma. J Thorac Oncol 11: 1879-1890, 2016.

10 Yearley JH, Gibson C, Yu N, Moon C, Murphy E, Juco J, Lunceford J, Cheng J, Chow LQM, Seiwert TY, Handa M, Tomassini JE and McClanahan T: PD-L2 expression in human tumors: Relevance to anti-PD-1 therapy in cancer. Clin Cancer Res 23: 3158-3167, 2017.

11 Takada K, Toyokawa G, Okamoto T, Akamine T, Takamori S, Katsura M, Fujishita T, Shoji F, Oda Y and Maehara Y: An immunohistochemical analysis of PD-L1 protein expression in surgically resected small cell lung cancer using different antibodies and criteria. Anticancer Res 36: 3409-3412, 2016.

Received September 12, 2018

Revised September 21, 2018

Accepted September 24, 2018 